\title{
BMJ Open What shape do UK trainees want their training to be? Results of a cross-sectional study
}

\author{
Rhiannon L Harries, ${ }^{1}$ Mustafa Rashid, ${ }^{2}$ Peter Smitham, ${ }^{2}$ Alex Vesey, ${ }^{3}$ \\ Richard McGregor, ${ }^{4}$ Karl Scheeres, ${ }^{5}$ Jon Bailey, ${ }^{6}$ Syed Mohammed Afzal Sohaib, ${ }^{7}$ \\ Matthew Prior, ${ }^{8}$ Jonathan Frost, ${ }^{8}$ Walid Al-Deeb, ${ }^{9}$ Gana Kugathasan, ${ }^{9}$ \\ Vimal J Gokani ${ }^{1}$
}

To cite: Harries $R L$, Rashid M, Smitham P, et al. What shape do UK trainees want their training to be? Results of a cross-sectional study. BMJ Open 2016;6: e010461. doi:10.1136/ bmjopen-2015-010461

- Prepublication history and additional material is available. To view please visit the journal (http://dx.doi.org/ 10.1136/bmjopen-2015010461).

Received 5 November 2015 Revised 12 July 2016 Accepted 20 July 2016

CrossMark

For numbered affiliations see end of article.

Correspondence to Rhiannon L Harries; president@asit.org

\section{ABSTRACT}

Objectives: The British Government is acting on recommendations to overhaul postgraduate training to meet the needs of the changing population, to produce generalist doctors undergoing shorter broad-based training (Greenaway Review). Only 45 doctors in training were involved in the consultation process. This study aims to obtain a focused perspective on the proposed reforms by doctors in training from across specialities.

Design: Prospective, questionnaire-based crosssectional study.

Setting/participants: Following validation, a 31-item electronic questionnaire was distributed via trainee organisations and Postgraduate Local Education and Training Board (LETB) mailing lists. Throughout the 10-week study period, the survey was publicised on several social media platforms.

Results: Of the 3603 demographically representative respondents, $69 \%$ knew about proposed changes.

Of the respondents, $73 \%$ expressed a desire to specialise, with $54 \%$ keen to provide general emergency cover. A small proportion (12\%) stated that current training pathway length is too long, although $86 \%$ felt that it is impossible to achieve independent practitioner-level proficiency in a shorter period of time than is currently required. Opinions regarding credentialing were mixed, but tended towards disagreement. The vast majority $(97 \%)$ felt credentialing should not be funded by doctors in training. Respondents preferred longer placement lengths with increasing career progression. Doctors in training value early generalised training $(65 \%)$, with suggestions for further improvement.

Conclusions: This is the first large-scale crossspecialty study regarding the Shape of Training Review. Although there are recommendations which trainees support, it is clear that one size does not fit all. Most trainees are keen to provide a specialist service on an emergency generalist background. Credentialing is a contentious issue; however, we believe removing aspects from curricula into post-Certificate of Completion of Training (CCT) credentialing programmes with shortened specialty training routes only degrades the current consultant expertise, and does not serve the

\section{Strengths and limitations of this study}

- This study describes the experiences of a crosssectional cohort of current trainees within the UK regarding the proposals described in the Shape of Training Review. The sample size provides a robust perspective on current opinions on postgraduate training and is $80 \%$ greater in number than the original Shape of Training Review consultation.

- The wide distribution of the survey in the UK and responses from all training grades, regions and specialties helped to mitigate against specialty subgroup selection bias. However, some specialties had higher response rates than others; this is likely to be explained by the varying degrees of penetration and distribution via specialty trainee groups combined with small number of respondents in the smaller specialties.

- It is recognised that there is an inherent selection bias in those who fully complete the survey.

- In this survey, we found a higher than expected incompletion rate $(20 \%)$. This may be as a result of a copy of the Shape of Training Review not being included at the start of the survey. Given that $24.7 \%$ of those who fully completed the questionnaire had not heard of the review, it could be hypothesised that many more who had not heard of the review failed to fully complete the survey. The demographics of those who did not fully complete the survey were comparable to those that did complete the survey, eliminating a potential completion bias of the respondents.

population. Educational needs, not political winds, should drive changes in postgraduate medical education and all stakeholders should be involved.

\section{INTRODUCTION}

Postgraduate medical training within the UK has seen several changes over the past few 
decades, most notably the 'Calman reforms', ${ }^{1}$ Modernising Medical Careers (MMC) ${ }^{2}$ and the introduction of the European Working Time Directive (EWTD). ${ }^{3}$ In 2013, Professor Sir David Greenaway published the Shape of Training Review, an independent review of postgraduate medical training. ${ }^{4}$ This report made recommendations for the future structure and delivery of postgraduate medical training. The review addresses a wide range of themes including changing patient needs, balance of the medical workforce (specialists or generalists), flexibility of training, the breadth and scope of training and tensions between service and training. The changes proposed in its 19 recommendations are far reaching, with implications for current and future trainees in the UK (box 1).

Despite the impact on current and future trainees, only 45 doctors in training were consulted as part of the Shape of Training Review. ${ }^{5}$ Several trainee bodies have since raised concerns regarding the implications of the recommendations. ${ }^{6-10}$

At the time of manuscript submission, the Academy of Medical Royal Colleges is undertaking a consultation and mapping process on the implementation of the Shape of Training Review recommendations. This study aims were to obtain widespread, representative doctors in training opinion on the proposals made by the Shape of Training Review.

\section{METHODS}

\section{Participants and setting}

Duration of postgraduate training in the UK varies between specialties ranging from 5 years (general practice) to a minimum of 10 years (surgical specialties) as a postgraduate. However, many trainees often take time

Box 1 Summary of the shape of training review's key recommendations

1. Full General Medical Council (GMC) registration should move to the point of graduation from medical school.

2. The foundation programme (FP) should continue as a 2-year programme, facilitating broad-based learning in community and secondary care settings.

3. Following the FP, doctors will enter 'broad-based specialty training' in a general area of practice, which will proceed for 4-6 years.

4. There will be the option of a single year to be taken within training to expand management/educational/clinical experience.

5. The Certificate of Completion of Training (CCT) will be replaced by a Certificate of Specialty Training (CST).

6. The future CST holder will be eligible to apply for consultant-level posts in the generality of their training area.

7. Subspecialty skills will be acquired after obtaining the CST by a process of 'credentialing'.

8. All changes in training (and therefore the products of the proposed training system) will be based on the local needs of the population.

Box adapted from Ferguson et al, 2014.7 out of programme to perform research, obtain higher degrees or undertake other valuable educational experiences. Competitive entry into the specialty of choice occurs following completion of the initial postqualification foundation programme (FP; a 2-year programme covering the generality of medicine, with full General Medical Council (GMC) registration occurring after the first year). A variety of run-through and 'uncoupled' (competitive entry at both core and higher training) training pathways exist depending on the specialty. A summary of the 63 training pathways recognised by the GMC are described in online supplementary appendix 1. At time of manuscript submission, there are currently 53825 doctors in training in the UK as recognised by the GMC. ${ }^{11}$

\section{Questionnaire design and distribution}

A 31-item, questionnaire was developed, consisting of free-text, binomial and five-point Likert scale responses. The questionnaire was designed with reference to previously published guidelines on questionnaire-based research. ${ }^{12-14}$ The survey tool was peer reviewed by experienced trainers and piloted by over 20 specialty trainees with a spread of seniority and specialty. Content validity was ensured by this peer review and piloting process. Given the range of different constructs measured, internal consistency calculations were not undertaken. The feedback received was used to refine the question items. Individual question items were compulsory. No individually identifiable information was collected (eg, email address); therefore, non-responders could not be identified for follow-up. No incentives were offered for participation. A copy of the questionnaire is included as supplemental information.

A SurveyMonkey (SurveyMonkey.com, LLC, Palo Alto, California, USA) online link to the survey was distributed to members of the authors' respective trainee doctors associations, as well as those listed in the Acknowledgements section. Further communications via local, regional and national mailing lists were sent periodically throughout the 10-week study period. Data collection took place from 25 May 2015 to 3 August 2015. The ethical dimensions of this non-mandatory evaluation survey were considered and no concerns were identified. Completion of the questionnaire was taken as implied consent to participate in this study.

This study was undertaken by several trainee associations: Association of Surgeons in Training (ASiT), British Orthopaedic Trainee Association (BOTA), Royal College of Physicians and Surgeons of Glasgow Trainees' Committee, Royal College of Surgeons of Edinburgh Trainees' Committee, Psychiatric Trainees' Committee (PTC), Emergency Medicine Trainees' Association (EMTA), British Junior Cardiologists Association (BJCA), Royal College of Obstetricians and Gynaecologists Trainees' Committee, and Society of Radiologist in Training (SRT). Further details can be found in online supplementary appendix 2 . 
Table 1 Specialties classified according to the approved specialty training curricula by Royal College, Faculty or Joint Board

\begin{tabular}{|c|c|}
\hline Surgical specialties & $\begin{array}{l}\text { Cardiothoracic surgery, general surgery, oral and maxillofacial surgery, otolaryngology surgery, } \\
\text { neurosurgery, paediatric surgery, plastic surgery, trauma and orthopaedics, urology, vascular surgery }\end{array}$ \\
\hline Medical specialties & $\begin{array}{l}\text { Allergy, audiological medicine, acute medicine, cardiology, clinical genetics, clinical } \\
\text { neurophysiology, clinical pharmacology and therapeutics, dermatology, endocrinology and } \\
\text { diabetes, gastroenterology, general internal medicine, genitourinary medicine, geriatric medicine, } \\
\text { haematology, immunology, infectious diseases, medical oncology, medical ophthalmology, } \\
\text { neurology, nuclear medicine, paediatric cardiology, palliative medicine, pharmaceutical medicine, } \\
\text { rehabilitation medicine, renal medicine, respiratory medicine, rheumatology, sport and exercise } \\
\text { medicine, tropical medicine }\end{array}$ \\
\hline Intensive care medicine & Intensive care medicine \\
\hline Anaesthesia & Anaesthesia \\
\hline Emergency medicine & Emergency medicine \\
\hline General practice & General practice \\
\hline $\begin{array}{l}\text { Obstetrics and } \\
\text { gynaecology }\end{array}$ & Obstetrics and gynaecology \\
\hline Ophthalmology & Ophthalmology \\
\hline Paediatrics & Paediatrics \\
\hline Pathology specialties & $\begin{array}{l}\text { Chemical pathology, diagnostic neuropathology, forensic histopathology, histopathology and } \\
\text { medical microbiology and virology }\end{array}$ \\
\hline Psychiatry specialties & $\begin{array}{l}\text { General psychiatry, child and adolescent psychiatry, forensic psychiatry, medical psychotherapy, } \\
\text { old age psychiatry and psychiatry of learning disability }\end{array}$ \\
\hline Public health & Public health \\
\hline Radiology specialties & Clinical radiology and clinical oncology \\
\hline
\end{tabular}

\section{Data analysis}

Trainees were asked to state the specialty they intended to pursue. Only specialties recognised by the GMC were included. For purposes of data analysis, specialties were grouped according to the approved specialty training curricula by Royal College, Faculty or Joint Board and are described in table 1. Community Sexual and Reproductive Health and Occupational Medicine were excluded from any specialty-specific data analysis due to small numbers of respondents. Junior trainees were defined as foundation doctor year 1-2 (FP1, FP2), core/specialty trainee year 1-2 (CT1/ST1, CT2/ST2) and core trainee year 3 (CT3). Senior trainees were defined as specialty trainee year 3-8 (ST3-8) and post-Certificate of Completion of Training (CCT) fellow. Figure 1 outlines the current training pathway for UK postgraduates in medicine by stages of training.

Only fully completed questionnaires were included in the analysis. Microsoft Excel (Microsoft, 2010, Redmond, Washington, USA) was used to calculate descriptive statistics. Statistical analysis was performed using Sigma Plot V.11 (Systat Software, UK) and statistical significance was accepted at $\mathrm{p}<0.05$. Significance testing was performed using $\chi^{2}$ test for non-parametric binary data. Free-text responses were independently categorised by theme into groups for analysis by two of the authors, with differences resolved by discussion. Survey sample size calculations were based on standard published formulae. ${ }^{14}$

\section{RESULTS}

\section{Respondent demographics}

A total of 3603 questionnaires were fully completed and included in the analysis. Medical students were excluded from the data analysis $(n=166)$. Nine hundred and eighty were excluded due to incompletion. The mean age of respondents was 32 years (range 23-61) and $53.1 \%$ were male. Respondents ranged from FP year 1 doctor (FP1) to post-CCT fellow. A summary of demographics of the respondents is provided in table 2.

\section{Shape of Training Review}

Of the completed survey responses, $75.3 \%$ (2713) of respondents stated they had heard of the Shape of Training Review; with senior trainees (ST3-post-CCT) more aware of the review than junior trainees (FP1-CT3; $68.3 \%$ vs $80.2 \%$; $95 \%$ CI $0.50 \%$ to $0.68 \%, \mathrm{p}<0.0001$ ) and male trainees more aware of the review than female trainees $(78.2 \%$ vs $72.2 \%$; $95 \%$ CI $0.62 \%$ to $0.84 \%$, $\mathrm{p}<0.001)$. Of those who responded that they had heard of the Shape of Training Review, 50.3\% (1367) stated they had read the report and $69.1 \%$ (1876) aware of the recommendations of the report.

\section{Broad-based training}

Only $17.6 \%$ of respondents stated they wanted to be a generalist clinician providing broad-based care based on themes; with emergency medicine and general practice statistically more likely to, compared with other specialties $(74.7 \%$ vs $12.7 \%$; $95 \%$ CI $15.40 \%$ to $27.30 \%$, $\mathrm{p}<0.0001)$. Overall, a third of trainees $(33.1 \%)$ want to be a generalist within their professional field; this varied between specialties from $73 \%$ in general practice and $68 \%$ in emergency medicine to just $10 \%$ in ophthalmology. Most $(73.1 \%)$ responded that they wish to be a specialist. Most common specialties aspiring to be a 


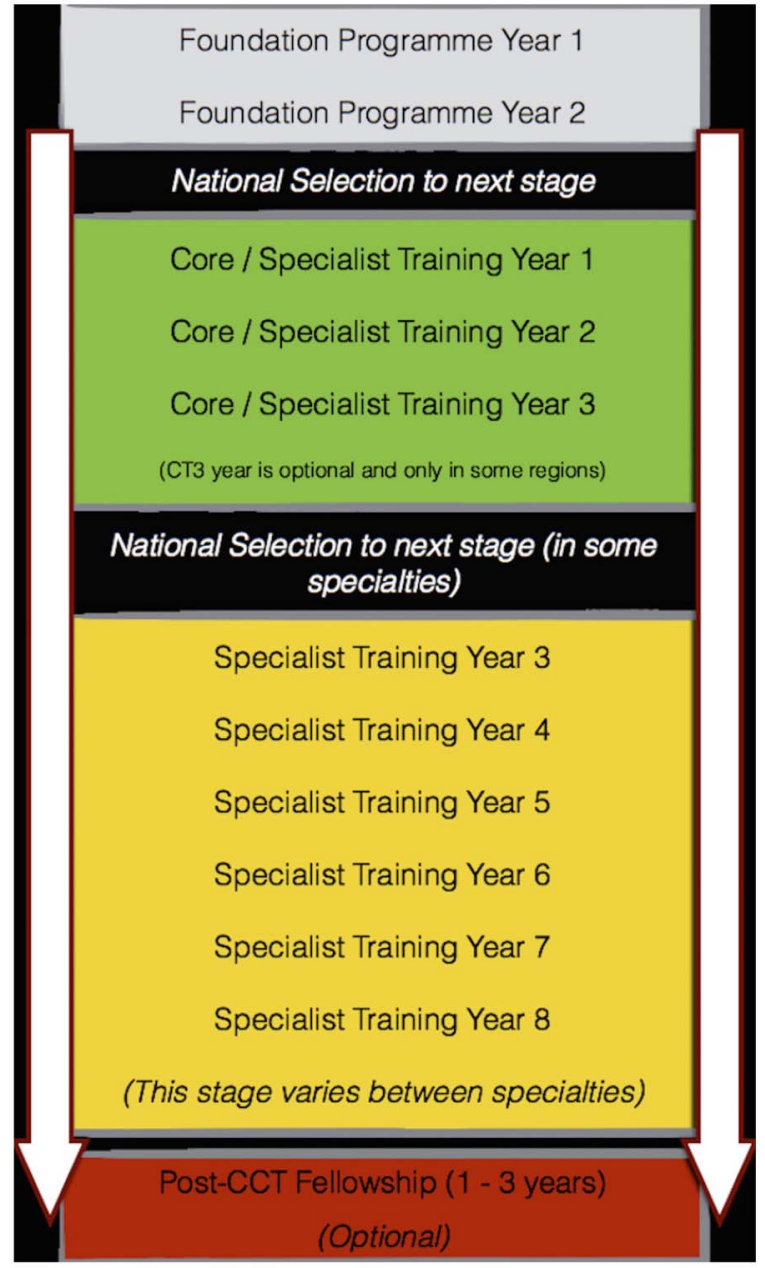

Figure 1 UK training pathway. CCT, Certificate of Completion of Training; CT3, core trainee year 3 .

specialist included surgery $(89.6 \%)$, medicine $(84.2 \%)$ and radiology $(82.4 \%)$. In total, $54.4 \%$ stated they want to be a specialist but still provide general on-call cover, with ophthalmology $(76 \%)$, surgery $(70.9 \%)$ and anaesthetics $(65.4 \%)$ most likely. Responses per specialty can be found in figure 2 .

A majority $(83.6 \%)$ of respondents stated they would prefer to be treated by a specialist if they were a patient, whereas in contrast, only $12.7 \%$ would prefer to be treated by a generalist if they were a patient. However, $69 \%$ would prefer to be treated by a specialist with a broad-based generalist training. Seventy per cent responded that they would prefer to be treated by a doctor who deals with a high volume of cases within a narrow specialised range of practice, and in comparison only $9 \%$ would prefer to be treated by a doctor who deals with a lower volume of cases within a broad generalised scope of practice.

\section{Length of training}

Overall, only $12.5 \%$ felt that the duration of their training pathway is too long with $61 \%$ volunteering that the training duration in their specialty is appropriate.
Interestingly, $21.8 \%$ (783) felt that training in their specialty is too short; with those pursuing a career in emergency medicine $(41.5 \%)$, general practice $(41.3 \%)$, pathology $(33.1 \%)$ and obstetrics and gynaecology $(31.4 \%)$ most likely to state their training duration could be lengthened (figure 3). Respondents were asked to provide free-text comments regarding the length of postgraduate training. Major themes identified included observations that the length of training could only be decreased if the burden of service provision was reduced (122) and that adequate time is needed to gain the breadth of experience necessary to practice independently (109). Several respondents also raised concerns that a decrease in training time would result in a subconsultant grade (51) or patient safety concerns (34); with some commenting that there is an evidence-based drive for specialisation that is at odds with the proposals in the Greenaway review (13). However, some respondents felt that a decrease in the length of training could be possible if less relevant specialties were removed from their training pathway (31) or they intended to become a generalist only (10).

Only $13.4 \%$ felt that a competent, independent practitioner in their specialty could be delivered in a shorter length of time within the current system, with those pursuing a career in ophthalmology $(28 \%)$ and paediatrics (23\%) most likely to respond positively yet still with a low agreement rate.

\section{Credentialing}

Overall, $37.7 \%$ of respondents felt there should be formalised specialist training post-CCT (eg, general surgery, medicine). In total, $58.5 \%$ felt there should be formalised subspecialist training post-CCT (eg, transplant surgery). Just $2.2 \%$ felt that credentialing should be funded or part-funded by the trainee. In total, $45.4 \%$ think that pre-CCT holders should have the same right to access credentialing as CCT holders. Forty-four per cent think that staff and associate specialist doctors (not on a formal training programme) not on the specialist register should have the same right to access credentialing as CCT holders, while only $13.3 \%$ felt that allied healthcare professionals should have the same right to access credentialing as CCT holders. However, in the free-text comments, 59 commented that they did not understand what the term credentialing meant.

\section{Length of placements}

Nearly two-thirds of respondents $(63 \%)$ felt that 6-month placements were appropriate for early years of postgraduate training, whereas $74 \%$ felt that 12 -month placements were appropriate for later years of postgraduate training.

\section{Point of registration}

Sixty per cent of all respondents were aware of the proposed change in the point of registration from completion of FP1 to qualification from medical school. 
Table 2 Respondent demographics

\begin{tabular}{|c|c|c|}
\hline Question & $\mathbf{N}$ & $\begin{array}{l}\text { Per } \\
\text { cent }\end{array}$ \\
\hline \multicolumn{3}{|l|}{ Gender } \\
\hline Male & 1879 & 52.15 \\
\hline Female & 1724 & 47.85 \\
\hline \multicolumn{3}{|l|}{ Grade } \\
\hline Foundation doctor (FP1-2) & 298 & 8.27 \\
\hline Core trainee (CT/ST1-CT3/SHO3+) & 923 & 25.63 \\
\hline Higher trainee (ST3-4) & 864 & 23.98 \\
\hline Higher trainee (ST5-6) & 790 & 21.93 \\
\hline Higher trainee (ST7-8) & 422 & 11.72 \\
\hline Research/clinical fellow & 138 & 3.83 \\
\hline Post-CCT & 112 & 3.11 \\
\hline Other & 56 & 1.55 \\
\hline Academic postholder & 308 & 8.55 \\
\hline Less than full-time trainee & 346 & 9.60 \\
\hline Military trainee & 95 & 2.64 \\
\hline \multicolumn{3}{|l|}{ Specialty you intend to pursue } \\
\hline Cardiothoracic surgery & 27 & 0.75 \\
\hline Otolaryngology surgery & 89 & 2.47 \\
\hline General surgery & 418 & 11.60 \\
\hline Neurosurgery & 54 & 1.50 \\
\hline Oral and maxillofacial surgery & 26 & 0.72 \\
\hline Paediatric surgery & 30 & 0.83 \\
\hline Plastic surgery & 89 & 2.47 \\
\hline Trauma and orthopaedics & 408 & 11.32 \\
\hline Urology & 88 & 2.44 \\
\hline Vascular surgery & 60 & 1.67 \\
\hline Allergy & 0 & 0.00 \\
\hline Audiological medicine & 1 & 0.03 \\
\hline Acute medicine & 26 & 0.72 \\
\hline Clinical genetics & 7 & 0.19 \\
\hline Clinical neurophysiology & 1 & 0.03 \\
\hline Cardiology & 128 & 3.55 \\
\hline Dermatology & 50 & 1.39 \\
\hline $\begin{array}{l}\text { Clinical pharmacology and } \\
\text { therapeutics }\end{array}$ & 1 & 0.03 \\
\hline Endocrinology and diabetes & 22 & 0.61 \\
\hline Gastroenterology & 61 & 1.69 \\
\hline General internal medicine & 19 & 0.53 \\
\hline Genitourinary medicine & 13 & 0.36 \\
\hline Geriatric medicine & 72 & 2.00 \\
\hline Haematology & 27 & 0.75 \\
\hline Immunology & 5 & 0.14 \\
\hline Infectious diseases & 32 & 0.89 \\
\hline Medical oncology & 11 & 0.31 \\
\hline Medical ophthalmology & 0 & 0.00 \\
\hline Neurology & 23 & 0.64 \\
\hline Nuclear medicine & 2 & 0.06 \\
\hline Paediatric cardiology & 6 & 0.17 \\
\hline Palliative medicine & 18 & 0.50 \\
\hline Pharmaceutical medicine & 0 & 0.00 \\
\hline Rehabilitation medicine & 4 & 0.11 \\
\hline Renal medicine & 16 & 0.44 \\
\hline Respiratory medicine & 39 & 1.08 \\
\hline Rheumatology & 23 & 0.64 \\
\hline Sport and exercise medicine & 4 & 0.11 \\
\hline Tropical medicine & 0 & 0.00 \\
\hline Intensive care medicine & 55 & 1.53 \\
\hline
\end{tabular}

Table 2 Continued

\begin{tabular}{|c|c|c|}
\hline Question & $\mathbf{N}$ & $\begin{array}{l}\text { Per } \\
\text { cent }\end{array}$ \\
\hline Anaesthesia & 324 & 8.99 \\
\hline $\begin{array}{l}\text { Community sexual and reproductive } \\
\text { health }\end{array}$ & 2 & 0.06 \\
\hline Emergency medicine & 101 & 2.80 \\
\hline General practice & 184 & 5.11 \\
\hline Obstetrics and gynaecology & 176 & 4.88 \\
\hline Occupational medicine & 16 & 0.44 \\
\hline Ophthalmology & 50 & 1.39 \\
\hline Paediatrics & 231 & 6.41 \\
\hline Chemical pathology & 16 & 0.44 \\
\hline Diagnostic neurophysiology & 3 & 0.08 \\
\hline Forensic histopathology & 2 & 0.06 \\
\hline Histopathology & 127 & 3.52 \\
\hline Medical microbiology and virology & 33 & 0.92 \\
\hline General psychiatry & 84 & 2.33 \\
\hline Child and adolescent psychiatry & 18 & 0.50 \\
\hline Forensic psychiatry & 21 & 0.58 \\
\hline Medical psychotherapy & 5 & 0.14 \\
\hline Old age psychiatry & 26 & 0.72 \\
\hline Psychiatry of learning disability & 13 & 0.36 \\
\hline Public health & 68 & 1.89 \\
\hline Clinical radiology & 115 & 3.19 \\
\hline Clinical oncology & 16 & 0.44 \\
\hline Unsure & 17 & 0.47 \\
\hline Total responses & 3603 & 100 \\
\hline
\end{tabular}

Around a third (32.7\%) felt that oversubscription of the FP is a current problem and $43.6 \%$ recognised that there is a current issue with medical schools having responsibility for FP1s who move to a different region to take up work from their medical school.

Only $11.8 \%$ were aware that the proposed change to the point of registration would make graduate-entry medical school programmes non-compliant with European Union (EU) Legislation, if medical school programmes remained only 4 years long. Out of all of the respondents, $11.9 \%$ stated they had undertaken a graduate-entry medical school training programme; with general practice $(17.9 \%)$, radiology $(16.7 \%)$ and ophthalmology (16\%) having the highest proportion of graduate-entry trainees.

Over half of respondents $(56.3 \%)$ felt that registration at the end of FP1 was beneficial; with $77.2 \%$ and $74.2 \%$ raising concerns that patient safety and FP1 supervision may be affected by proposed change in the point of registration, respectively. In total, $37.2 \%$ would be in support of the introduction of a national licensing examination prior to qualification from medical school.

\section{Flexibility of training}

Majority of respondents (89.6\%) agreed that additional flexibility should be built into postgraduate training, with junior trainees more likely to agree than senior trainees $(91.7 \%$ vs $88.4 \%$; $95 \%$ CI $1.14 \%$ to $1.85 \%$, 


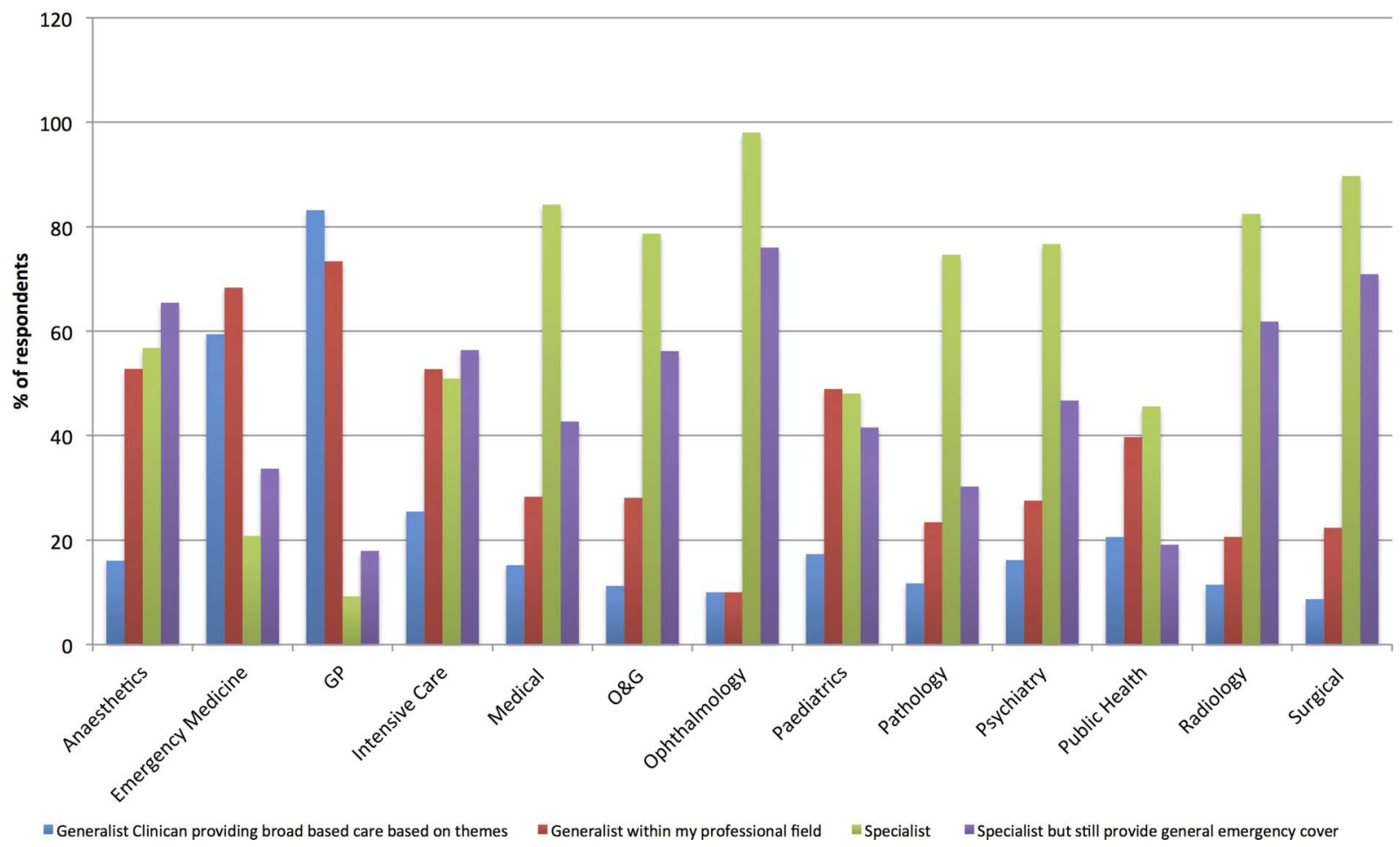

Figure 2 Responses per specialty when asked regarding type of independent practitioner trainees aspired to. GP, general practice; O\&G, obstetrics and gynaecology.

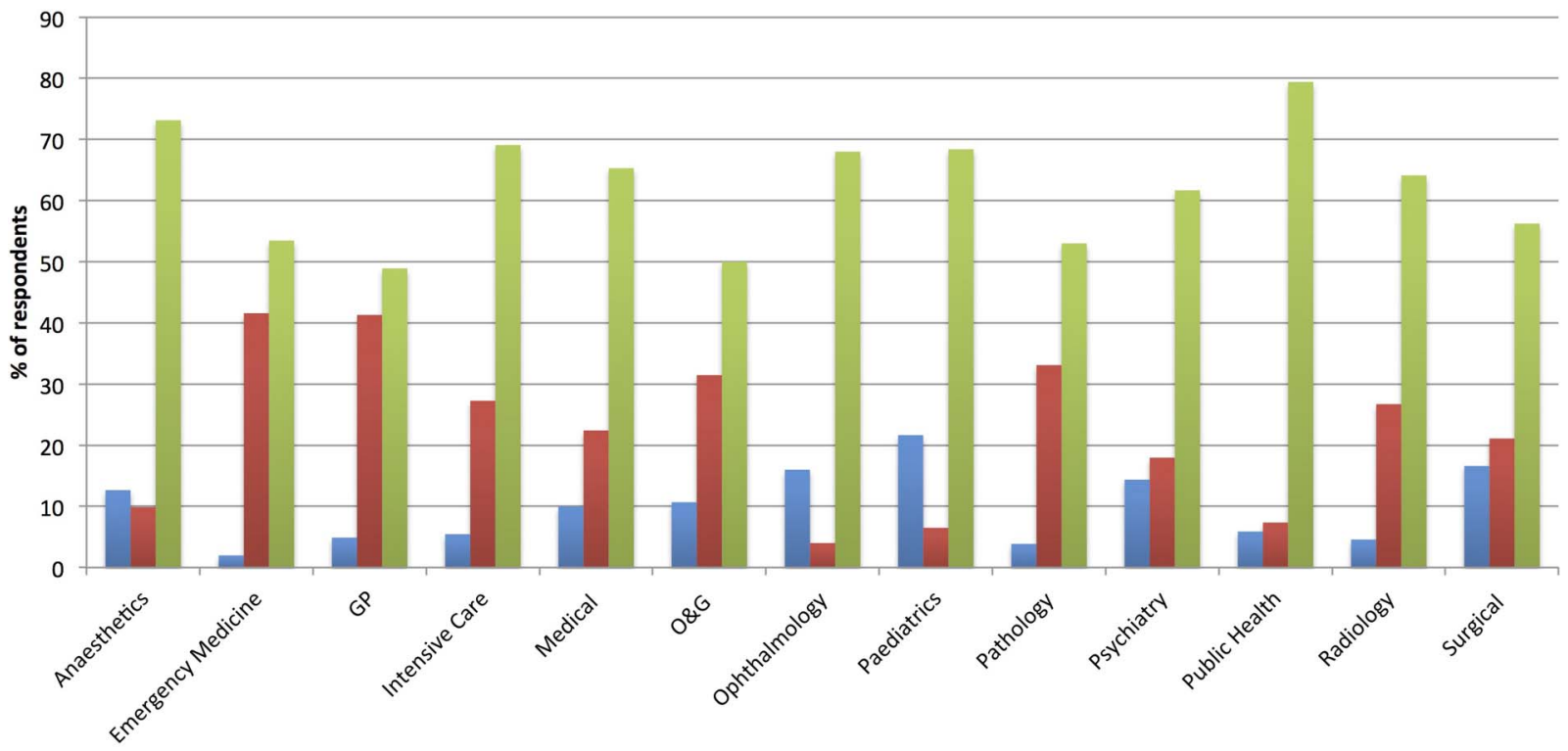

- Presently, Training in my specialty is too long Presently, Training in my specialty is too short Length of training in my specialty is appropriate

Figure 3 Responses per specialty when asked about the length of training in their specialty. GP, general practice; O\&G, obstetrics and gynaecology.

$\mathrm{p}<0.001)$ and female trainee more likely to agree than male trainees $(92.4 \%$ vs $87.0 \%$; $95 \%$ CI $1.46 \%$ to $2.28 \%$, $\mathrm{p}<0.001)$. In total, $74.9 \%$ felt a limitation on out of programme opportunities to a maximum of 1 year would be of concern to them. Over a third of all respondents
(38.2\%) stated they have or intended to take 2 years or more out of programme for either research, experience, career break or training (figure 4); most commonly noted within medicine (56.7\%), public health (50\%), obstetrics and gynaecology $(45.5 \%)$ and surgery (42\%). 


\section{Current training}

Overall $4.3 \%$ felt their training curriculum is too specialist and $11.3 \%$ felt their training curriculum is too generalist. In total, $10.4 \%$ felt their training curriculum requires a major overhaul to address the needs of patients; however, $42.5 \%$ felt their training curriculum requires minor modifications to address the needs of patients. In total, $71.8 \%$ felt that core training (CT1-2/ ST1-2) in their specialty was a valuable experience. Just under two-thirds $(64.7 \%)$ stated that core training in their specialty could be improved to include more training opportunities. Trainees pursuing surgery, medicine and paediatrics were most likely to state that their specialty core training could be improved to include more training opportunities $(80.5 \%, 73.3 \%$ and $70.1 \%$, respectively), and trainees pursuing pathology and anaesthetics least likely (23.7\% and $26.2 \%$, respectively). In total, $69.5 \%$ recognised benefit to undertaking rotations in specialties closely related to theirs at core trainee level.

\section{Improving training}

Respondents were asked to provide free-text comments on how training could be improved. A breakdown of the major themes is provided in box 2. Most common themes were dedicated protected training experiences (347), a reduction in service provision (282), flexibility for out of programme experiences (134), experience of related specialties to specialty of choice (122) and improved trainer supervision (105). A representative sample of these is provided in box 3 .

\section{DISCUSSION}

The results of this cross-sectional study have revealed that one in four UK doctors in training had not heard of the Shape of Training Review. This is a major review into the changes in medical training, which the authors believe has not been adequately publicised within the profession. Of those that had heard of the review, only $3.7 \%$ had been involved in the consultation process. Most doctors in training have not had the opportunity to feed into the review that represents a complete overhaul of their training pathway. Any discussions related to proposed changes affecting postgraduate training should have adequate representation from all stakeholders.

Perhaps unsurprisingly, emergency medicine and general practice trainees were more likely to aspire to be a clinician delivering broad-based care compared with other specialties; with surgery, medicine and radiology trainees more likely to aspire to become specialists. A recent survey by the BJCA found that $74 \%$ of cardiology trainees thought their training was too short. ${ }^{15}$ Subsequently, the GMC approved an extension to cardiology training to ST8 for those choosing to dual accredit in cardiology with general medicine. However, the longitudinal survey data found a sharp drop off in number of trainee's dual accrediting, thus supporting a trend of lengthening training due to the demand for achievement of competency in the specialist skills within the specialty. There is a plethora of evidence to support that practitioners performing high volume of procedures result in more favourable patient outcomes across a range of specialties. ${ }^{16-23}$ It is this evidence that has led to the recent drive of centralisation of complex hospital services such as resectional upper gastrointestinal surgery, neurosurgery and neuroradiology, vascular surgery, gynaecological oncology surgery, cardiothoracic surgery and thoracic radiology, major trauma, bone and soft tissue sarcoma surgery and limb reconstruction surgery. Rather than reducing the number of specialists, the authors believe that training should be augmented to ensure that specialists also have sufficient general and emergency skills. However, the wide variation in responses by specialty outlines that a one size fits all approach is misguided.

Only $13 \%$ felt that it would be possible to deliver an independent practitioner in a shorter period of time within the current system. This major change would require a shift of workload towards an increase in dedicated training alongside a lesser commitment to service provision, with potentially supernumerary posts. Given the current financial difficulties facing the National Health Service (NHS) alongside a potential crisis in

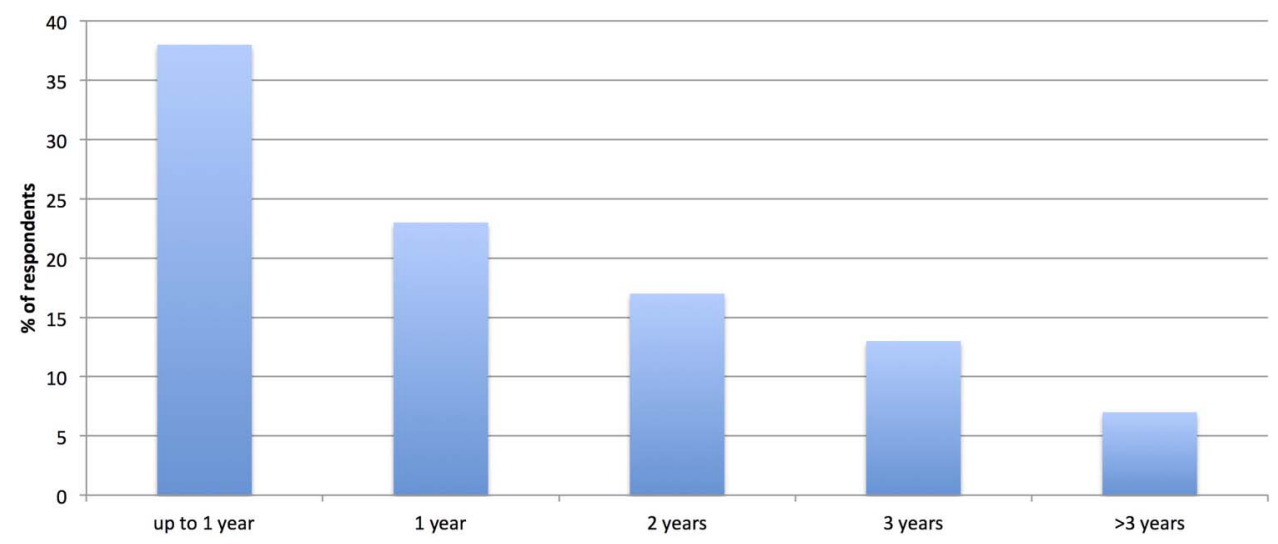

Figure 4 Number of years trainees have or intend to take out of programme. 
Box 2 Respondents recommendations to improve postgraduate training

Trainer improvements:

- More dedicated time to train;

- Increased engagement in training;

- Better supervision;

- Reward/incentivise good training;

- Accountability to allow opportunities to meet the trainee's learning needs;

- Training the trainers in work-based assessments and e-portfolio;

- Increased mentorship and career advice;

- Production of a structured training timetable.

Local Education and Training Board (LETB)/Health Board improvements:

- Feedback on training placements which is acted on by LETBs;

- Poor training placements to have trainees removed;

- Adequate notice for new or changed rota and penalties when notice is under 6 weeks;

- Adequate notice for placements so relocations can be planned;

- Trainees to be placed in recognised high-quality training unit.

Training programme improvements:

- Dedicated and protected training experiences;

- Bespoke training based on an individual's learning needs;

- Increase the length of time for core training and reduce the foundation programme to 1 year;

- Themed core training programmes;

- Experience placements in specialties closely related to chosen specialty;

- Increased flexibility for out of programme research/experience/career breaks/training;

- Interdeanery placements to gain subspecialty experience;

- Priority to be given to trainees' for training experiences over allied healthcare professionals (AHPs);

- Management and leadership experience;

- More community placements for general practice and paediatrics;

- More specialty/subspecialty experience in later years;

- Programme not time limited/lengthen training duration;

- Less cross-cover emergency work;

- Increase working hours/relaxation of European Working Time Directive (EWTD);

- More robust Annual Review of Competence Progression (ARCP) processes;

- Time allocated for non-clinical activities including audit, quality improvement and e-portfolio.

Improve teaching:

- More formal teaching sessions;

- Protected teaching time;

- More study leave to allow attendance on teaching sessions or courses;

- Ability to take study leave and not restricted by service provision;

- Better access to simulation facilities.

Improve morale:

- Increased access to less than full-time training;

- Work-life balance;

- No undermining, bullying or discriminatory behaviour;

- Trainees to be treated as professionals by seniors, managers and colleagues.

Decrease service provision:

- Less night shifts;

- Less on-call shifts;

- Less ward duties at core training level;

- On-call shifts to include more training opportunities and assessments by seniors;

- Rotas to be filled;

- Increase the number of Staff and Association Specialty (SAS) doctors to cover service provision;

- Better use of AHPs for service provision to allow training opportunities to occur.

Improved e-portfolio:

- Less focus on quantity of work-based assessments;

- Less focus on indicative numbers of procedures;

- More user friendly e-portfolio systems;

- Trainer engagement and knowledge of e-portfolio.

Increased funding:

- More funding into training resources;

- Increased study budget;

- Reduction in the costs of conferences, course, training fees and examination fees;

Salaries that reflect the workload and responsibilities of a doctor in training. 
Box 3 Representative qualitative comments from respondents regarding recommendations for improving training

- "A greater focus on training. In fact just some training, period!"

- "Make trainers more accountable for training outcomes, eg, numbers, quality of assessment, quality of supervision. They should come to the ARCP."

- "If training were to include rotations in closely related specialties, I would not want it to be taken from the time we already have."

- "Radiology training is perfect. Keep your mitts off it."

- "Core training should not be about service provision."

- "The Shape of training recommendation goes against what is happening in the rest of the world. While the United States, Canada and European Union are heading to specialty \& sub specialty focused training, I find it amusing reading about the shape of training recommendations."

- "It's shocking the lack of general medicine training given (a) the number of trainees (b) the amount of training money attached to these trainees (where does it go?) (c) The number of patients admitted through general medicine (d) ageing population (e) need for generalists etc. I would suggest: protected teaching time (regular half days twice weekly), adequately staffed rotas (paying internal locums is much better than getting people from agencies), stop wasting our time with e-portfolio 'evidencing' and other such nonsense ie, largely box ticking and not training, use the skills labs, teach everyone ultrasound and get them competent in it, simulation training, let people know rota greater than 6 weeks in advance with some sort of punishment for the health board if this isn't done."

- "Adequate supervision, and clearly defined standards of supervision."

- "Stop hospitals from treating us as temporary annoyances."

- "The ability to tailor our own training programme."

- "Flexibility and a more individual approach. Some people know what they want to do so tailoring appropriate experience would be better than a one size fits all approach."

- "More clued up educational supervisors and training programme directors who actually do things to help you rather than just sit down and make you sign forms that don't actually help you become a better trainee. Deanery-level initiatives to ensure that only interested educational supervisors are chosen and that their outcomes are monitored yearly, just as trainees are. Simple improvements include genuine specific and achievable learning objectives for each year to help trainees to focus their activities, with reference to how other trainees in your specialty have fared with these, so we can all learn from each other.-Also, it feels like whenever you made any comment or symptom about your training, you are not believed or considered to hold a minority opinion (even when there is documentation that you hold the majority view!!)."

recruitment and retention on the horizon the opinion from doctors in training would suggest that shortening postgraduate training is untenable within the current NHS infrastructure.

Nearly all (98\%) respondents stated that trainees should not fund credentialing; this is likely due to the ever-rising costs of medical training. Under the current $£ 9000$ annual fees regime, medical students graduate with debts exceeding $£ 39000$, from university tuition fees alone. ${ }^{24}$ Whereas when additional Student Loans Company (SLC) loans are required for maintenance, debt exceeds $£ 81$ 000. Furthermore, doctors in training shoulder the burden of costs of postgraduate training. Compulsory training courses, conference attendance, medical indemnity, GMC registration, British Medical Association membership and Royal College or Faculty membership examinations and fees mean the costs for meeting the essential criteria for entry into higher specialist training range from $£ 2215$ for anaesthetics, £2375 for emergency medicine, £2815 for medical specialties, and $£ 3360$ for surgical specialties (with exclusion of oral and maxillofacial surgery which totals $£ 20780$ due to requirement of a bachelor of dentistry degree). ${ }^{25}$ These costs do not disappear on entering specialist training, rather they continue to increase including all the continued costs previously described and often additionally including higher degree and fellowship expenses. ${ }^{26}$ The authors feel strongly that in light of the increasing burden of medical training costs, any proposals for credentialing should be at no additional expense to the trainee.

Aside from funding, there were mixed views with regard to credentialing and this may revolve around the current uncertainty among trainees about what credentialing may include. Only 1 in 10 respondents stated that credentialing should be accessible to allied healthcare professionals. Currently the GMC does oversee physician assistants similar to allied healthcare professionals and therefore further work investigating their accountability, continued professional development and role in ensuring doctors in training are provided with additional training opportunities is required before the same credentials are available for all healthcare professionals.

Over a 10th of those who completed the survey had undertaken a graduate-entry medical school training programme. If the proposal for a change in the point of registration were implemented, potentially it would result in a loss in those individuals, which may affect the diversity of the workforce. With general practice, radiology and ophthalmology having the highest proportion of those who were graduate entry, this may have a knock-on effect for recruitment into these specialties. However, the reason behind why these specialties had higher proportions of those from graduate-entry medical training programmes was not explored within this study. Approximately three-quarters of trainees raised concerns related to patient safety and FP1 supervision if a change in the point of registration were to be 
implemented. Prior to any proposed change in the point of registration, we would recommend that the effects on patient safety and FP1 supervision be rigorously investigated in further detail. The drivers for the change are still unclear; both oversubscription of the FP and concerns regarding medical schools having little responsibility for FP1s who move out of region have both been suggested. Concerns exist that altering the point of registration to qualification will not address oversubscription, and in fact may worsen the problem due to the potential increase of EU graduates eligible to apply.

Just over a third of respondents stated they were in favour of a national licensing examination that would occur at the end of medical school. National licensing examinations may serve to ensure a high-quality and standard of medical education, and are essential to practice in Canada and the USA (Medical Council of Canada Qualifying Examination and US Medical Licensing Examination, respectively). Currently within the UK, there are a wide range of differing teaching styles delivered across medical schools, all of which rigorously assess a student's ability to be a safe and competent doctor on qualification. Prospective students may opt for the training programme that suits their learning style best when applying to universities. A national licensing examination may deter from the variety of teaching programmes currently offered, to the detriment of diversity within the workforce and may increase the assessment burden for undergraduate.

Just under two-thirds (64.7\%) stated that core training in their specialty could be improved to include more training opportunities, with surgical specialties scoring highest $(80 \%)$. This is reflected in the GMC National Training Survey $2014^{27}$ results where surgery showed the lowest satisfaction ratings; however, this was mostly seen at foundation $(72 \%)$ and core level $(77 \%)$ when compared with higher specialist training level $(85 \%)$. The GMC Survey 2014 also found that programme specialty doctors training to be general practitioners (GPs) had the lowest scores for clinical supervision $(89 \%)$; however, when analysis was performed looking at postspecialty instead, GP had one of the highest scores for clinical supervision, suggesting that doctors in GP training receive better supervision when in GP practices compared with other rotations. This was supported by freetext comments in our survey that suggested that GP trainees in hospital specialties were used to fill rotas and received poor training exposure. Medical specialties scored lowest for adequate practical experience in the GMC National Training Survey 2014, presumable due to requirement to cover service provision, which again was supported by the free-text comments in our survey.

However, despite the negative responses discussed, $69 \%$ of trainees stated they would see benefit to undertaking specialties closely related to theirs in the early years of training. This is an area in which training programmes could be enhanced in order to improve postgraduate training.

\section{RECOMMENDATIONS}

Relevant issues currently witnessed within UK postgraduate training include greater need for trainer engagement, improved balance of service provision in favour of training exposure, improvement in junior doctors morale, improved teaching opportunities and improvements made at a training programme level and health board level. Based on the qualitative feedback provided in this study, recommendations for improving postgraduate training, together with the content and availability of information provided, are summarised in box 2 . Addressing these issues alone is likely to result in an improvement in postgraduate training.

\section{CONCLUSIONS}

The results from this study provide evidence of a lack of support for some the key proposals made in the Shape of Training Review. The authors feel the Review failed to adequately include doctors in training during their consultation process, despite being the future workforce of the NHS. We would welcome a new, independent review be commissioned with widespread stakeholder engagement from the outset. The wide variation in responses by specialty highlights that a one size fits all may not be the best way forward.

\section{Author affiliations}

${ }^{1}$ Association of Surgeons in Training Council, Association of Surgeons in Training, London, UK

${ }^{2}$ British Orthopaedic Trainees Association, British Orthopaedic Association Offices, London, UK

${ }^{3}$ Royal College of Physicians and Surgeons in Glasgow Trainees' Committee, Glasgow, UK

${ }^{4}$ Royal College of Surgeons of Edinburgh Training Committee, Edinburgh, UK ${ }^{5}$ Psychiatric Trainees' Committee, Royal College of Psychiatrists, London, UK

${ }^{6}$ Emergency Medicine Training Association, Royal College of Emergency Medicine, London, UK

${ }^{7}$ British Junior Cardiologists Association, British Cardiovascular Society, London, UK

${ }^{8}$ Royal College of Obstetricians and Gynaecologists Trainees' Committee, London, UK

${ }^{9}$ The Society of Radiologists in Training, Wrexham, UK

Twitter Follow Rhiannon Harries at @rhiharries, Jon Bailey at @DrJonBailey and Vimal Gokani at@VimalGokani

Acknowledgements The authors gratefully acknowledge the British Association of Dermatologists, British Society of Gastroenterology, Faculty of Intensive Care Medicine, Faculty of Public Health, Group of Anaesthetists in Training, Health Education North West, Health Education North West London, Health Education South London, Health Education Wessex, Health Education Yorkshire and Humber, National Research Collaborative, NHS Education for Scotland, Northern Ireland Medical and Dental Training Agency, Paediatric Rheumatology Trainees Group, Royal College of Anaesthetists, Royal College of Paediatric and Child Health, Royal College of Pathologists, Scottish Academy of Medical Royal Colleges Trainee Doctors Group, STARSurg, UK Haematology Trainees' Group, Wales Deanery and Welsh Respiratory Trainees' Group for distributing the survey to their trainee members. The authors additionally thank all those trainees who took the time to complete the survey.

Contributors RLH and VJG conceived and designed the study. All authors designed the questionnaire. RLH collected the data. RLH and VJG analysed 
the data. All authors were responsible for compiling the manuscript and approving the final article.

Funding This research received no specific grant from any funding agency in the public, commercial or not-for-profit sectors.

Competing interests The authors are current specialist trainees and elected members of their respective trainee organisation.

Provenance and peer review Not commissioned; externally peer reviewed.

Data sharing statement Respondent-level data are available from the corresponding author at president@asit.org. The presented data are anonymised and risk of identification is low.

Open Access This is an Open Access article distributed in accordance with the Creative Commons Attribution Non Commercial (CC BY-NC 4.0) license, which permits others to distribute, remix, adapt, build upon this work noncommercially, and license their derivative works on different terms, provided the original work is properly cited and the use is non-commercial. See: http:// creativecommons.org/licenses/by-nc/4.0/

\section{REFERENCES}

1. Calman K, Department of Health. Hospital Doctors-Training for the Future. 1993

2. Tooke J. Aspiring to excellence-Findings and Final Recommendations of the Independent Inquiry into Modernising Medical Careers. 2008.

3. Temple J. Time for Training-A review of the impact of the European Working Time Directive on the quality of training. 2010.

4. Greenaway D, ed. Securing the future of excellent patient care. http://www.shapeoftraining.co.uk/static/documents/content/Shape of_training_report_Final_Report.pdf_53900462.pdf (accessed 22 Oct 2015).

5. Greenaway D, ed. Securing the future of excellent patient care: annexes. http://www.shapeoftraining.co.uk/static/documents/content/ Annexes_and_Appendices_final.pdf_53854144.pdf (accessed 22 Oct 2015).

6. BMA. Response to the Shape of Training Review 'and unprecedented show of professional unity'. 2014. https:// communities.bma.org.uk/my working life/b/weblog/archive/2015/01/ 08/response-to-the-shape-of-training-review-39-an-unprecedentedshow-of-professional-unity-39 (accessed 22 Oct 2015).

7. Ferguson HJM, Fitzgerald JEF, Beamish AJ. Implications of the shape of training review for surgery. Ann R Coll Surg Engl (Suppl) 2014;96:357-9.

8. Glaseby J, McElnay $\mathrm{P}$, Ferguson $\mathrm{H}$, et al. Proposals for shortening UK surgical training will directly impact on patient safety. Ann Surg 2015.
9. Gokani VJ, McElnay PJ, Beamish AJ, et al. Association of Surgeons in Training. Further concerns about the Shape of Training proposals. BMJ 2015;350:h3219.

10. Hollick RJ, Ripley DP, Walesby KE. Shaping the future of our training. J R Coll Physicians Edinb 2015;45:100-3.

11. Correspondence from Kevin Connor, General Medical Council (19 Aug 2015).

12. Jones TL, Baxter MA, Khanduja V. A quick guide to survey research. Ann $R$ Coll Surg Engl 2013;95:5-7.

13. Eysenbach $\mathrm{G}$. Improving the quality of web surveys: the CHEcklist for Reporting Results of Internet E-Surveys (CHERRIES). J Med Internet Res 2004;6:e34.

14. Bartlett JE, Kotrlik JW, Higgins CC. Organizational research: determining appropriate sample size in survey research. Inf Technol Learn Perform J 2001;19:43-50.

15. Afzal Sohaib SM, Bates MGD, Sarwar R, et al. Quantifying the challenges of specialty training : the 2013 British Junior Cardiologist's Association Survey. Br J Hosp Med (Lond) 2014;74:402-5.

16. Birkmeyer JD, Siewers AE, Finlayson EVA, et al. Hospital volume and surgical mortality in the United States. N Engl J Med 2002;346:1128.

17. Jollis JG, Romano PS. Volume-outcome relationship in acute myocardial infarction. JAMA 2000;284:3169-71.

18. Dudley RA, Johansen $\mathrm{KL}$, Brand $\mathrm{R}$, et al. Selective referral to high-volume hospitals: estimating potentially avoidable deaths. JAMA 2000;283:1159-66.

19. Ananthakrishnan AN, McGinley EL, Saeian K. Higher hospital volume is associated with lower mortality in acute nonvariceal upper-GI haemorrhage. Gastrointest Endosc 2009;70:422-32.

20. Begg CB, Cramer LD, Hoskins WJ, et al. Impact of hospital volume on operative mortality for major cancer surgery. JAMA 1998;280:1747-51.

21. Halm EA, Lee $C$, Chassin MR. Is volume related to outcome in health care? A systematic review and methodologic critique of the literature. Ann Intern Med 2002;137:511-20.

22. Reames BN, Ghaferi AA, Birkmeyer JD, et al. Hospital volume and operative mortality in the modern era. Ann Surg 2014;260:244-51.

23. Archampong D, Borowski D, Wille-Jørgensen $\mathrm{P}$, et al. Workload and surgeon's specialty for outcome after colorectal cancer surgery. Cochrane Database Syst Rev 2012;(3):CD005391.

24. Ercolani MG, Vohra RS, Carmichael F, et al. The lifetime cost to English students of borrowing to invest in a medical degree: a gender comparison using data from the Office of National Statistics. BMJ Open 2015;5:e007335.

25. Stroman L, Weil S, Butler K, et al. Can you afford to become a surgeon? The bill, please. The Bulletin of the Royal College of Surgeons of England, 2015.

26. Smitham $\mathrm{P}$, Rashid M, Kahane S, et al. The financial implications of training within the UK system. J Trauma Orthop 2015;3:44.

27. General Medical Council. National Training Survey. 2014. http://www gmc-uk.org/NTS_2014_KFR_A4.pdf_56706809.pdf (accessed 22 Oct 2015) 